\title{
Challenges Facing Emergency Medicine Residents in Saudi Arabia: A Cross-Sectional Study
}

\author{
Aisha Alqahtani
}

\begin{abstract}
Background: Challenges related to the residency programme differ according to residents' roles, interactions, culture, responsibilities and expectations.

Aim: This study aims to explore the challenges faced by emergency medicine physicians during their residency programme. We also aim to investigate the influence of several demographic variables on their training experience.

Method: This is a cross-sectional study, conducted in Saudi Arabia from June, 2021 to July 2021, using a survey designed by the author.

Results: The total number of participants was 37. Of these, $24.3 \%(n=9)$ were $R 1$ residents, $10.8 \%(n=4)$ were $R 2,35.1 \%$ $(n=13)$ were $R 3$, and $29.7 \%(n=11)$ were $R 4$. While most of the participants $(89 \%)$ clearly understood which reference to use for studying, only $56.7 \%$ had a clear understanding of how to study for the exams. Reading club was advocated by $72 \%$ of participants, and only half the participants had a positive perception of leading, preparing, and discussing topics during academic activity. Of all the residency levels, $R 3$ residents were the most supportive of having expert physician guidance during ED procedures, $p=0.04$. Other factors given more importance by $\mathrm{R} 3$ residents than by other levels were mentorship, $p=0.051$, and having a course review for the exam, $p=0.001$.

Conclusion: This study uncovers several challenges reported by participants from different residency levels. We noted that the R3 training level, being a period of transition from junior to senior level, is a significant period requiring more attention; more emphasis on mentorship and reading club is advocated.
\end{abstract}

Index Terms-Emergency medicine Training Challenges, Residency challenges

\section{INTRODUCTION}

Residency training programmes differ by structure, experiences, faculty, education and personal support, all of which may or may not be influencing factors during the resident's learning journey. Nevertheless, working in different settings within the hospital is associated with specific challenges. For example, being part of the emergency residency programme entails working in a setting characterised by stress, uncertainty, a noisy and crowded environment, the presence of concerned caretakers, and heavy workloads [1,2] [1]. While those factors cannot be modified, there is a need to explore modifiable factors. The educational system, clinical experiences, coaching, evaluation, and expectations can all be adjusted to meet the trainees' needs.

The challenges may be viewed in relation to the training programme or in relation to the environment. The latter include

Aisha Alqahtani is with Emergency Department, King Fahed Medical City, Saudi Arabia (Corresponding author). knowledge of the medical health care system, organisational differences and systemic processes [3], and were the leading cause of burnout [4]. However, the training programme and the environment are interrelated, and efforts directed at one will influence the other. Furthermore, a third factor worth considering relates to the trainees themselves. The residents' expectations, work-life balance, handling of time pressures, fear of failure or making mistakes, developing the requisite clinical skills for the speciality [5], and their demographics are indeed essential to analyse, as these are cited as factors associated with psychosocial stress [6] and may therefore be determinants for the success of the training journey.

The paucity of the literature and the diverse opinions call for a more in-depth analysis of specific challenges faced by emergency training residents, exploring particularly those challenges that may be influenced by demographics, level of training, and the educational activity within the training programme. Knowing and addressing these challenges in appropriate and realistic ways will be crucial for the support and training of both juniors and seniors during their residency. This study, therefore, explores the challenges faced by emergency medicine residents during their training programme in Saudi Arabia, focusing on the influence of demographic variables and level of training on their expectations.

\section{METHODS}

This is a cross-sectional study, conducted from June, 2021 to July 2021. The author designed the survey and included questions about studying during training and for exams, academic activity, mentorship and supervision, and social life. Those dimensions stem from a pilot study of a random 11 emergency medicine residents, in which residents were asked to complete a survey to select from predefined challenges, and to cite any further challenges they believed essential.

The second phase of this study involved the distribution of the survey to a larger segment, using online platforms and social media.

We used the five-point Likert scale to capture residents' perceptions. We calculated the mean and standard deviation for age and used Fisher's exact test. We used STATA version 17.0 to analyse the data. The IRB committee has approved this study; the registered number is $21-317$.

\section{RESULTS}

The pilot study of 11 participants revealed concerns relating to the clarity of the resources from which residents are 
required to read (in general and particularly for the exams), whether it is more beneficial to study alone or in groups, and time management. We also noted concerns about productivity during duty days compared with days off, and presenting and leading a discussion as part of academic activity. Reading club was advocated; mentorship and supervision were also noted as essential factors during training.

In the second phase, the total number of participants was 37 . The mean age was 27.6 years $(\mathrm{SD}=1.67)$, with a range from 25-32 years. The participants' demographics are detailed in Table 1. "Strongly agree" and "agree" are combined under "positive response", while "strongly disagree" and "disagree" fall under "negative response" for each question, as illustrated in Table 2.

While most participants $(89 \%)$ clearly understood which references to use for studying, only $56.7 \%$ had a clear understanding of how to study for the exam. Moreover, an organised course review was supported by the majority (83.7\%). Although a slightly lower percentage, two thirds reported understanding the pros and cons of studying alone versus in groups.

A reading club was advocated by $72 \%$ of participants; only half the participants had a positive perception of leading, preparing and discussing topics during academic activity. $62 \%$ supported mentorship, whereas $94 \%$ supported direct expert supervision while performing procedures.

With regard to social life, we found that $40.5 \%$ were neutral about whether emergency medicine residency impacted their social relationships, while one third reported a negative impact. Lastly, a comfortable atmosphere for studying did not appear easy to create during duty days, as only $16 \%$ reported being comfortable studying on those days.

\section{Gender difference:}

The gender difference between residents did not emerge as an influencing factor for any of the abovementioned questions, $\mathrm{p}>0.05$; illustrated in Table 3 .

\section{Marital status:}

We noted no difference between married, single and divorced participants in their perception of the influence of the training programme on their social relationships, and in their ability to create a comfortable atmosphere for studying during working days versus days off; $\mathrm{p}>0.05$.

\section{Level of residency:}

Support for expert physician guidance during ED procedures appears to differ according to training level, $\mathrm{p}=0.04$. R3 residents showed the greatest support, while R1 and R2 were less supportive of expert guidance. This is illustrated in Table 3. Mentorship was another factor more highly supported by R3 residents than those of other levels, $\mathrm{p}=0.051$, as was having a course review before the exam, $\mathrm{p}=0.001$. R4 residents were less supportive than R3 of both mentorship and the exam course review, but more supportive than the junior levels.

\section{DISCUSSION}

Creating an ideal training programme is no easy task, and a step-by-step approach to improvement is realistic. Perhaps exploring the challenges and impeding factors is the first step in improving the training journey. In this study, we noted challenges specific to emergency medicine residents in Saudi Arabia; those include challenges related to studying, exams, mentorship, as well as social life. For instance, despite thehigh number of residents who reported a clear understanding of which study references to use during their residency training, almost half did not have a clear understanding of how to study for the exam. This discrepancy explains the high number who supported having a course review before the exam and those in support of reading clubs. Thus, we argue for the need to train residents for the exam, or for the exam to imitate daily practice.

Moreover, inquiry into academic activity revealed low enthusiasm for preparing, leading and managing discussions during the academic day. Probably the static method of presentation calls for more engagement, or for a lower workload on the presenter. In addition, we noted a high number in support of a reading club, despite such clubs not being a standard method of learning in Saudi emergency medicine training programmes. These learning activities often pertain to journal club [7], rather than reading the reference book to elaborate and comment on the text. Nonetheless, the effectiveness of reading from the reference book was not examined in the literature. We believe it is time to incorporate this into the academic activity, given the high number of residents from different levels who supported this method. We expect several benefits, including integrating real examples while reading the text, overcoming the language barrier, and integrating the latest evidence. We also argue that it will foster a shared understanding and enhance the reading skills of the residents. From another perspective, we noted that junior residents were less likely than seniors to support expert physician guidance during ED procedures. Imaginably this is related to their entrylevel experience in performing procedures, and that guidance for the basic steps is satisfactory. It also indicates that supervision by senior residents appears sufficient to teach them the different ED procedures.

The advantage of mentorship during residency training has been emphasised in the literature [8]. It was found to foster an excellent informal relationship [9], providing guidance and enhancing the learning journey $[10,11]$. R3 level residents are the most supportive of mentorship compared with those from other levels. Although one might argue for the role of mentorship only in early training, we noted another crucial period for mentorship, which is at the start of seniority: the R3 year. This phase should be deemed as essential as R1; the new role of leading the shift and supervising other residents is critical for the emergency residents' training journey. We therefore emphasise mentorship, especially during this period. Another interesting phenomenon is the plea for a pre-exam course review for R3 residents, as is provided for R1. It is possible that these R3 residents may be overwhelmed by high expectations and the pressure of managing a team, and more emphasis on their learning journey should not be overlooked. The social life of residents needs further exploration. The relatively high percentage of those who believe their social life to be affected should be examined in greater depth, and the 
mentor should be continuously available to assist with such issues.

\section{CONCLUSION}

This study provides a new perspective on the challenges facing emergency residents. However, our small sample size might threaten the generalisability of the data, despite not being confined to residents from one hospital. We therefore urge a replication of this analysis on a broader segment of residents within specific hospitals, to detect similarities or differences to our findings and to act accordingly. Overall, the learning capacity and work efficiency of residents can be improved. Challenges often are setting-related, but may also relate to the structure of the training programme and to the individual residents themselves.

\section{REFERENCES}

[1] Veasey S, Rosen R, Barzansky B, Rosen I, Owens J (2002). Sleep Loss and Fatigue in Residency Training. JAMA, 288(9), 1116. doi: 10.1001/jama.288.9.1116.

[2] Kelly SP, Shapiro N, Woodruff M, Corrigan K, Sanchez LD, Wolfe RE. The effects of clinical workload on teaching in the emergency department. Acad Emerg Med. 2007 Jun;14(6):526-31. doi: 10.1197/j.aem.2007.01.024. Epub 2007 May 4. PMID: 17483400.

[3] Khattab E, Sabbagh A, Aljerian N, Binsalleeh H,

Almulhim M, Alqahtani A, Alsalamah M (2019). Emergency medicine in Saudi Arabia: a century of progress and a bright vision for the future. International Journal of Emergency Medicine, 12(1). doi: 10.1186/s12245-019-0232-0.:

[4] Martin AR. Stress in residency: a challenge to personal growth. J Gen Intern Med. 1986;1(4):252-257. doi:10.1007/BF02596195.:

[5] Aalam A, Zocchi M, Alyami K, Shalabi A, Bakhsh A, Alsufyani A, et al. (2018). Perceptions of emer- gency medicine residents on the quality of residency train- ing in the United States and Saudi Arabia. World Journal of Emergency Medicine, 9(1), 5. doi: 10.5847/wjem.j.19208642.2018.01.001.:

[6] Alosaimi FD, Kazim SN, Almufleh AS, Alad- wani BS, Alsubaie AS. Prevalence of stress and its determinants among residents in Saudi Arabia. Saudi Med J. 2015;36(5):605-612. doi:10.15537/smj.2015.5.10814.:

[7] Gottlieb M, King A, Byyny R, Parsons M, Bailitz J. Jour- nal Club in Residency Education: An Evidencebased Guide to Best Practices from the Council of Emergency Medicine Residency Directors. West J Emerg Med. $2018 \quad$ Jul;19(4):746- $755 . \quad$ doi: 10.5811/westjem.2018.4.37507. Epub 2018 May 15. PMID: 30013715; PMCID: PMC6040913.

[8] Ramanan RA, Taylor WC, Davis RB, Phillips RS. Mentoring matters. Mentoring and career preparation in internal medicine residency training. J Gen Intern Med. 2006 Apr;21(4):340-5. doi: 10.1111/j.15251497.2006.00346. $\quad$ x. PMID: 16686809; PMCID: PMC1484727.
[9] Cohee BM, Koplin SA, Shimeall WT, Quast TM, Hartzell JD. Results of a Formal Mentorship Program for Internal Medicine Residents: Can We Facilitate Genuine Mentorship? J Grad Med Educ. 2015 Mar;7(1):105-8. doi: 10.4300/JGME-D-14-00315.1. PMID: 26217434; PMCID: PMC4507898.

[10] Cetnar AJ. Model for implementation of a modern journal club in medical physics residency programs. J Appl Clin Med Phys. 2021 Jun;22(6):253-261. doi: 10.1002/acm2.13250. Epub 2021 May 13. PMID: 33987945; PMCID: PMC8200434.

[11] Bhatia K, Takayesu JK, Nadel ES. A novel mentorship programme for residents integrating academic development, clinical teaching and graduate medical education assessment. Perspect Med Educ. 2016 Feb;5(1):56-9. doi: 10.1007/s40037015-0236-2. PMID: 26811193; PMCID: PMC4754222. 
Table 1. Participants' demographics

\begin{tabular}{ccc} 
Demographic & Variables & N (\%) \\
\hline \multirow{2}{*}{ Gender } & Male & $13(35.1)$ \\
& Female & $24(64.9)$ \\
Marital status & Single & $26(70.3)$ \\
& Married & $9(24.3)$ \\
& Divorced & $2(5.4)$ \\
Residency level & R1 & $9(24.3)$ \\
& R2 & $4(10.8)$ \\
& R3 & $13(35.1)$ \\
& R4 & $11(29.7)$
\end{tabular}

Table 2. Participants' responses

\section{Question}

You clearly understand from which references

you need to study.

You have a clear understanding of the pros and cons of studying alone versus in a study group.

Do you think you clearly understand how to study for the exam (books, MCQs)?

Do you think it is beneficial to have an organised course for curriculum review before an exam?

Do you support having a reading club, in which you read a chapter from a book in the presence

$$
\text { of a consultant? }
$$

Do you agree that preparing lectures and journal club presentations are a waste of your time, with not much benefit? (Reversed question)
Response

Positive response

Neutral

$3(8.1)$

Negative response

$1(2.7)$

Positive response

Neutral

$12(32.4)$

Negative response

$2(5.4)$

Positive response

$21(56.7)$

Neutral

8 (21.6)

Negative response

8 (21.6)

Positive response

$31(83.7)$

Neutral

$5(13.5)$

Negative response

Positive response

27 (72.9)

Neutral

$5(13.5)$

Negative response

$5(13.5)$

Positive response

$19(51.3)$

Neutral

$6(16.2)$

Negative response 
Do you think having expert physician guidance

is helpful to improve ED procedure skills?

Do you think having a mentor is an effective

way of providing guidance and support?

You feel that being a member of this profession negatively affects your social relationships.

(Reversed question)

You can more easily create a comfortable atmosphere for studying on your days off, than

on working days.
Positive response

35 (94.6)

Neutral

$1(2.7)$

Negative response

Positive response

Neutral

Negative response

$9(24.3)$

Positive response

$10(27)$

Neutral

Negative response

Positive response

$29(78.3)$

Neutral

Negative response

Table 3. Influence of gender and residency training level on residents' responses

\begin{tabular}{|c|c|c|}
\hline Variables & $\begin{array}{l}\text { Gender difference } \\
\qquad(p \text {-value })\end{array}$ & $\begin{array}{l}\text { Residency level }(p- \\
\text { value })\end{array}$ \\
\hline You clearly understand from which references you need to study. & 0.057 & 0.221 \\
\hline $\begin{array}{l}\text { You have a clear understanding of the pros and cons of studying } \\
\text { alone versus in a study group. }\end{array}$ & 1 & 0.958 \\
\hline $\begin{array}{l}\text { Do you think you clearly understand how to study for the exam } \\
\text { (books, MCQs)? }\end{array}$ & 0.651 & 0.305 \\
\hline $\begin{array}{l}\text { Do you think it is beneficial to have an organised course for } \\
\text { curriculum review before an exam? }\end{array}$ & 0.543 & $<0.001$ \\
\hline $\begin{array}{l}\text { You can more easily create a comfortable atmosphere for studying } \\
\text { on your days off, than on working days. }\end{array}$ & 0.205 & 0.081 \\
\hline $\begin{array}{l}\text { You feel that being a member of this profession negatively affects } \\
\text { your social relationships. }\end{array}$ & 0.935 & 0.204 \\
\hline $\begin{array}{l}\text { Do you support having a reading club, in which you read a chapter } \\
\text { from a book in the presence of a consultant? }\end{array}$ & 0.849 & 0.245 \\
\hline $\begin{array}{l}\text { Do you agree that preparing lectures and journal club presentations } \\
\text { are a waste of your time, with not much benefit? }\end{array}$ & 0.171 & 0.991 \\
\hline $\begin{array}{l}\text { Do you think having expert physician guidance is helpful to } \\
\text { improve ED procedure skills? }\end{array}$ & 0.886 & 0.04 \\
\hline $\begin{array}{l}\text { Do you think having a mentor is an effective way of providing } \\
\text { guidance and support? }\end{array}$ & 0.098 & 0.051 \\
\hline
\end{tabular}

